\title{
Temporal variation in community structure of zoosporic fungi in Lake Biwa, Japan
}

\author{
Peixue Song ${ }^{1,2, *}$, Rong $\mathrm{Yi}^{2,3}$, Shoko Tanabe ${ }^{2}$, Naoshige Goto ${ }^{2}$, Kensuke Seto ${ }^{4}$, \\ Maiko Kagami ${ }^{4}$, Syuhei Ban ${ }^{2}$ \\ ${ }^{1}$ School of City and Architecture Engineering, Zaozhuang University, Zaozhuang 277160, Shandong, PR China \\ ${ }^{2}$ School of Environmental Science, The University of Shiga Prefecture, 2500 Hassaka-cho, Hikone, Shiga 522-8533, Japan \\ ${ }^{3}$ School of Geography and Environmental Engineering, Gannan Normal University, Ganzhou 341000, Jiangxi, PR China \\ ${ }^{4}$ Faculty of Environment and Information Sciences, Yokohama National University, 79-7 Tokiwadai, Hodogaya-ku, \\ Yokohama 240-8501, Japan
}

\begin{abstract}
Zoosporic fungi play an important role in aquatic environments, but their diversity, especially that of parasitic fungi of phytoplankton, has still not been fully revealed. We conducted monthly analyses of the community structure of zoosporic fungi at a pelagic site in Lake Biwa, Japan, from May to December 2016. Metabarcoding analysis, targeted to a large subunit region of ribosomal DNA in the nano-size fraction of particles $(2-20 \mu \mathrm{m})$, was carried out on the samples. We also counted large phytoplankton and chytrid sporangia attached to the hosts. We detected 3 zoosporic fungal phyla (Blastocladiomycota, Chytridiomycota and Cryptomycota) within 107 operational taxonomic units (OTUs), in which Chytridiomycota was the most diverse and abundant phylum. Few fungal OTUs overlapped between months, and specific communities were detected in each month. These results showed that diverse zoosporic fungi with high temporal variability inhabited the lake. Five large phytoplankton species were found to be infected by chytrids: Staurastrum dorsidentiferum, S. rotula, Closterium aciculare, Asterionella formosa and Aulacoseira granulata. Some chytrids were detected by metabarcoding analysis: Zygophlyctis asterionellae infecting A. formosa, Staurastromyces oculus infecting S. dorsidentiferum and Pendulichytrium sphaericum infecting $A$. granulata. One OTU detected in association with infected C. aciculare by microscopic counting might have been an obligate parasitic chytrid of C. aciculare. The results indicated that a combination of metabarcoding and microscopic analysis revealed more information on zoosporic fungi, including those that are parasitic.
\end{abstract}

KEY WORDS: Zoosporic fungi - High-throughput sequencing • LSU rDNA • Chytrid · Community diversity

\section{INTRODUCTION}

Zoosporic fungi include facultative and obligate parasites and saprotrophs, belonging mainly to the phyla Chytridiomycota, Blastocladiomycota, Neocallimastigomycota, Cryptomycota and Aphelidiomycota (James et al. 2006, Hibbett et al. 2007, Karpov et al. 2014, Letcher \& Powell 2018), and they play important roles in aquatic environments (Kagami et al. 2007a, Frenken et al. 2017, Grossart et al. 2019,

\footnotetext{
${ }^{*}$ Corresponding author: songpeixue1990@163.com
}

Yoneya et al. 2021). Among zoosporic fungi, Chytridiomycota and Aphelidiomycota are prominent parasites of phytoplankton not only in freshwater lakes (Kagami et al. 2006, Karpov et al. 2014), but also in marine ecosystems (Garvetto et al. 2019, Kilias et al. 2020). Zoosporic fungi release motile zoospores that attach to the surface of host phytoplankton cells. These zoospores have often been miscounted as flagellates, owing to their uncharacteristic morphological features (Kagami et al. 2007b, Lefèvre et al. 2007,

() The authors 2021. Open Access under Creative Commons by Attribution Licence. Use, distribution and reproduction are unrestricted. Authors and original publication must be credited. 
Jobard et al. 2010). Parasitic chytrids potentially influence food web dynamics by transferring nutrients and energy from large phytoplankton cells to zooplankton, in a process known as the 'mycoloop' (Kagami et al. 2007a).

Recently, the taxonomy of zoosporic fungi has been greatly expanded with the development of molecular phylogenetics and ultrastructure analysis (Frenken et al. 2017). However, owing to missing DNA reference data, parasitic fungi are often not identifiable, even by deep amplicon sequencing. Phylogenetic analysis could assign taxonomic positions of unidentifiable sequences and shed light on their ecology based on phylogenetic positions (Seto et al. 2020). Counting fungal sporangia attached to host phytoplankton cells is helpful in identifying the parasitic fungi of phytoplankton. Combining microscopic counts and metabarcoding analysis may improve the detection of parasitic fungi and allow us to understand the community structure of zoosporic fungi.

In Lake Biwa, the largest lake in Japan, parasitic chytrids have been observed to infect the dominant green alga, Staurastrum dorsidentiferum, and to influence its temporal dynamics and material flows (Kagami \& Urabe 2002, Kagami et al. 2004). Diverse fungi including Cryptomycota and Aphelidiomycota, as well as Chytridiomycota, have also been detected from different phytoplankton species in Lake Biwa by analysis of the single sporangium-like cell attached to a phytoplankton cell or colony (Ishida et al. 2015). The spatio-temporal dynamics of these hostparasite relationships in Lake Biwa remain uncertain. High-throughput sequencing of the internal transcribed spacer 2 (ITS2) region of ribosomal DNA (rDNA) revealed fungal communities in Lake Biwa; however, only 1 zoosporic fungal phylum (Chytridiomycota) was detected (Song et al. 2018). The ITS2 region of chytrids is too variable for alignment by phylogenetic analysis, and not many chytrid ITS2 sequences have been deposited in databases yet (Frenken et al. 2017, Heeger et al. 2019). The large subunit (LSU) region of rDNA has less genetic variation than the ITS2 region, but has adequate variation for chytrids, and many sequences of known chytrid species have already been deposited in databases and have been applied to analyze chytrid communities in several lakes (Lefèvre et al. 2012, Wurzbacher et al. 2016). In the present study, we determined the community structure of zoosporic fungi using highthroughput sequencing and phylogenetic analysis of the LSU region of rDNA extracted from nano-sized particles $(2-20 \mu \mathrm{m})$, to clarify the diversity and tem- poral variation in the zoosporic fungal community in Lake Biwa. Chytrid sporangia attached to phytoplankton were also counted by staining, using epifluorescence microscopy to identify the parasitic chytrids infecting host phytoplankton.

\section{MATERIALS AND METHODS}

\subsection{Sample collection}

Water samples were collected monthly from 6 May to 12 December 2016, when phytoplankton were abundant, with a Van Dorn sampler (volume: 10 l) from each depth at 1,3,5,10 and $15 \mathrm{~m}$ at Stn $3(70 \mathrm{~m}$ deep, $\left.35^{\circ} 19.8^{\prime} \mathrm{N}, 136^{\circ} 08.9^{\prime} \mathrm{E}\right)$ in the north basin of Lake Biwa (mean depth, $41.2 \mathrm{~m}$ ), Japan. For molecular analyses, equal volumes $(500 \mathrm{ml})$ of water collected from each depth were mixed and combined into 1 sample; this was because chytrid distribution and any environmental parameters were vertically homogeneous above $15 \mathrm{~m}$ during the study period (Figs. S1 \& S2 in the Supplement at www.int-res. com/articles/suppl/a087p017_supp.pdf). All biotic and abiotic parameters were therefore calculated as averages throughout the 0-15 m water column (Table S1). The samples for molecular analysis were transferred to the laboratory within $2 \mathrm{~h}$ in an insulated container to keep the samples cold. Aliquots of the samples from each depth for counting phytoplankton and chytrid sporangia cells attached to the host phytoplankton were preserved immediately after collection with buffered formalin at a final concentration of $1 \%$. Vertical profiles of water temperature were determined with a CTD profiler (JFE Advantech, ACL1183-PDK) on each sampling occasion.

\subsection{Phytoplankton and sporangia counts}

Large phytoplankton $(>20 \mu \mathrm{m})$ species were identified and counted under a light microscope (Olympus, BX-50) at a magnification of $400 \times$. Chytrid sporangia attached to the host cells were stained with calcofluor white and counted with blue fluorescence under excitation and emission wavelengths of 385 and $440 \mathrm{~nm}$, respectively (Kagami et al. 2007a), using an epi-fluorescence microscope (Olympus, BX-51) at a magnification of 100-1000x. The prevalence of infection for each phytoplankton species was calculated as the percentage of phytoplankton cells with chytrid sporangia out of the total number of phytoplankton cells. 


\subsection{DNA extraction}

The combined water sample from each depth was pre-filtered through a $20 \mu \mathrm{m}$ mesh net for separating zoosporic fungi (2-5 $\mu \mathrm{m}$ in diameter) from other, larger fungi and those attached to the host phytoplankton and substrates. Next, $500 \mathrm{ml}$ of the filtrate were filtered again through a $2.0 \mu \mathrm{m}$ pore size membrane filter (Millipore) to collect the zoospores. DNA was extracted directly from the membrane filter with the DNeasy ${ }^{\circledR}$ Plant Mini Kit (Qiagen ${ }^{\circledR}$ ). DNA concentration was measured with a Qubit fluorometer (Invitrogen). The extracted DNA was frozen at $-20^{\circ} \mathrm{C}$ until analysis.

\subsection{Metabarcoding analysis using Illumina MiSeq}

Metabarcoding analysis targeted the fungal-specific LSU regions, which were amplified using the primers LR3R (5'-GTC TTG AAA CAC GGA CC-3') (Rehner \& Samuels 1995) and LR5 (5'-TCC TGA GGG AAA CTT CG-3') (Hopple \& Vilgalys 1994). All PCR reactions were conducted in $20 \mu \mathrm{lmixes}$ with Takara Ex TaqHS mix, $0.2 \mu \mathrm{M}$ of both forward and reverse primers and $\sim 1 \mathrm{ng}$ of extracted DNA. The first PCR cycling consisted of initial denaturation at $94^{\circ} \mathrm{C}$ for $2 \mathrm{~min}$; followed by 25 cycles of denaturation at $94^{\circ} \mathrm{C}$ for $30 \mathrm{~s}$, annealing at $52^{\circ} \mathrm{C}$ for $30 \mathrm{~s}$ and elongation at $72^{\circ} \mathrm{C}$ for $30 \mathrm{~s}$; and then a final extension at $72^{\circ} \mathrm{C}$ for $5 \mathrm{~min}$. To attach the index sequence to the first PCR products, the second PCR products were processed with the primer set $2^{\text {nd }} F$ : AAT GAT ACG GCG ACC ACC GAG ATC TAC AC-Index2 (8 bp)-ACA CTC TTT CCC TAC ACG ACG $C$ and $2^{\text {nd }} \mathrm{R}$ : CAA GCA GAA GAC GGC ATA CGA GAT-Index1 (8 bp)-GTG ACT GGA GTT CAG ACG TGT G (Table S2). The second PCR cycling consisted of initial denaturation at $94^{\circ} \mathrm{C}$ for $2 \mathrm{~min}$; followed by 8 cycles of denaturation at $94^{\circ} \mathrm{C}$ for $30 \mathrm{~s}$, annealing at $60^{\circ} \mathrm{C}$ for $30 \mathrm{~s}$ and elongation at $72^{\circ} \mathrm{C}$ for $30 \mathrm{~s}$; and then a final extension at $72^{\circ} \mathrm{C}$ for $5 \mathrm{~min}$. The library quality was assessed using a Fragment Analyzer system. The libraries were sequenced on an Illumina MiSeq platform and $250 \mathrm{bp}$ paired-end reads were generated. We obtained 1112173 raw reads from all samples collected, and all raw reads were deposited in the NCBI Sequence Read Archive (SRA) database under accession number SRP119396.

\subsection{DNA amplification and sequencing}

Barcodes and PCR primers were removed from the raw reads by the fastq_barcode_splitter from the
Fastx toolkit software (ver. 0.0.13.2). Low-quality reads (values $<20$ ) were trimmed using Sickle software (ver. 1.33). High-quality reads were processed to merge paired-end reads of each sample through FLASH software (ver. 1.2.10) (Magoč \& Salzberg 2011). After these processes, the reads obtained were screened by USEARCH software (ver. 8.0.1623i86linux64) to find chimera sequences (Edgar 2010). Finally, effective reads were generated by removing these chimera sequences, and singletons were removed. UPARSE software (Edgar 2013) was used to cluster effective reads of all samples. Effective reads with $97 \%$ similarity were classified into 1 operational taxonomic unit (OTU). Taxonomic assignments were based on assign_taxonomy.py scripts of Quantitative Insights Into Microbial Ecology software (QIIME, ver. 1.9.0) (Caporaso et al. 2010). Data that contained the term 'no BLAST hit' in the taxonomic annotation were removed. All OTUs that were not assigned to fungi were discarded from the analysis. OTU sequences belonging to fungi were submitted to the DNA data bank of Japan (DDBJ) Mass Submission System (MSS) under accession numbers LC323648-LC324677. Zoosporic fungal sequences (i.e. phyla Blastocladiomycota, Chytridiomycota, Cryptomycota and Neocallimastigomycota) were selected for the downstream analysis.

\subsection{Statistical analysis}

OTU composition and relative abundances of zoosporic fungal assemblages derived from the DNA amplification and sequencing results in each month were calculated to clarify taxonomic diversity in the zoosporic fungal community in the lake. In order to visualize the number of unique OTUs detected in each month, we used Gephi software (ver. 0.9.1), which is a tool for discovering the connectivity among the OTUs tested. Prior to the statistical analyses, a rarefied OTU table was generated by QIIME rarefaction analysis script with the rarefied depth in the minimum sequence number. Chao-1 (Chao 1984) and Shannon's H (Shannon 2001) indices were calculated as representatives of alpha diversity in fungal communities.

\subsection{Phylogenetic analysis}

In order to determine which OTUs were closely related to those of cultured chytrids by molecular phylogenetic analysis, we created a data set of LSU 
rDNA sequences of the class Chytridiomycetes. Abundant and/or unique Chytridiomycetes OTUs were selected and added into the data set. Three species of the class Monoblepharidomycetes were selected as outgroup taxa. Sequences were automatically aligned with MAFFT (Katoh \& Standley 2013). Ambiguously aligned regions were excluded using 'trimAl' (Capella-Gutiérrez et al. 2009) with the 'gappyout' option. The maximum likelihood tree was inferred using RAxML 8.2.7 (Stamatakis 2014). We ran an analysis under the GTRGAMMAI model and used the '-fa' option to conduct a rapid bootstrap analysis with 1000 replicates combining 200 searches for the optimal tree.

\section{RESULTS}

\subsection{Physicochemical environment and host phytoplankton}

According to vertical profiles of water temperature, lake water was vertically stratified from June to September, when the temperature gradually decreased below $5 \mathrm{~m}$ (Fig. S1). However, most of the physicochemical parameters other than temperature were vertically homogeneous above $15 \mathrm{~m}$ even in the stagnation period (Fig. S1).
We found a total of 12 large phytoplankton species comprising 1 dinoflagellate (Ceratium hirundinella), 6 green algae (Closterium aciculare, Micrasterias hardyi, Staurastrum arctiscon, S. dorsidentiferum, S. rotula, Xanthidium hastiferum) and 5 diatom species (Aulacoseira granulata, Asterionella formosa, Aulacoseira nipponica, Fragilaria crotonensis, Synedra sp.) (Fig. 1). According to the vertical profiles of the dominant phytoplankton species and chytrid sporangia that attached to their hosts, all were almost uniformly distributed throughout the 0-15 m water column (Fig. S2). Therefore, average abundances throughout the 0-15 m water column are shown in the results. Green algae were always the dominant group at $>50 \%$ of the total counted phytoplankton abundance, while diatoms and dinoflagellates comprised $<38$ and $<12 \%$, respectively, throughout the study period. S. dorsidentiferum was the most dominant species among the phytoplankton ( $>30 \%$ of total abundance) from May until September and had its highest density of $18.0 \times 10^{3}$ cells $1^{-1}$ in August, while $M$. hardyi increased abruptly from October and had its highest density of $78.0 \times 10^{3}$ cells $1^{-1}$ in December.

Chytrid sporangia were found on 5 out of 12 large phytoplankton species (Figs. $2 \& 3$ ). The prevalence of infection differed among phytoplankton species: the percentages of infected $S$. dorsidentiferum



Fig. 1. Species composition and cell densities of phytoplankton from 6 May to 12 December 2016 at Stn 3 in the north basin of Lake Biwa, Japan 

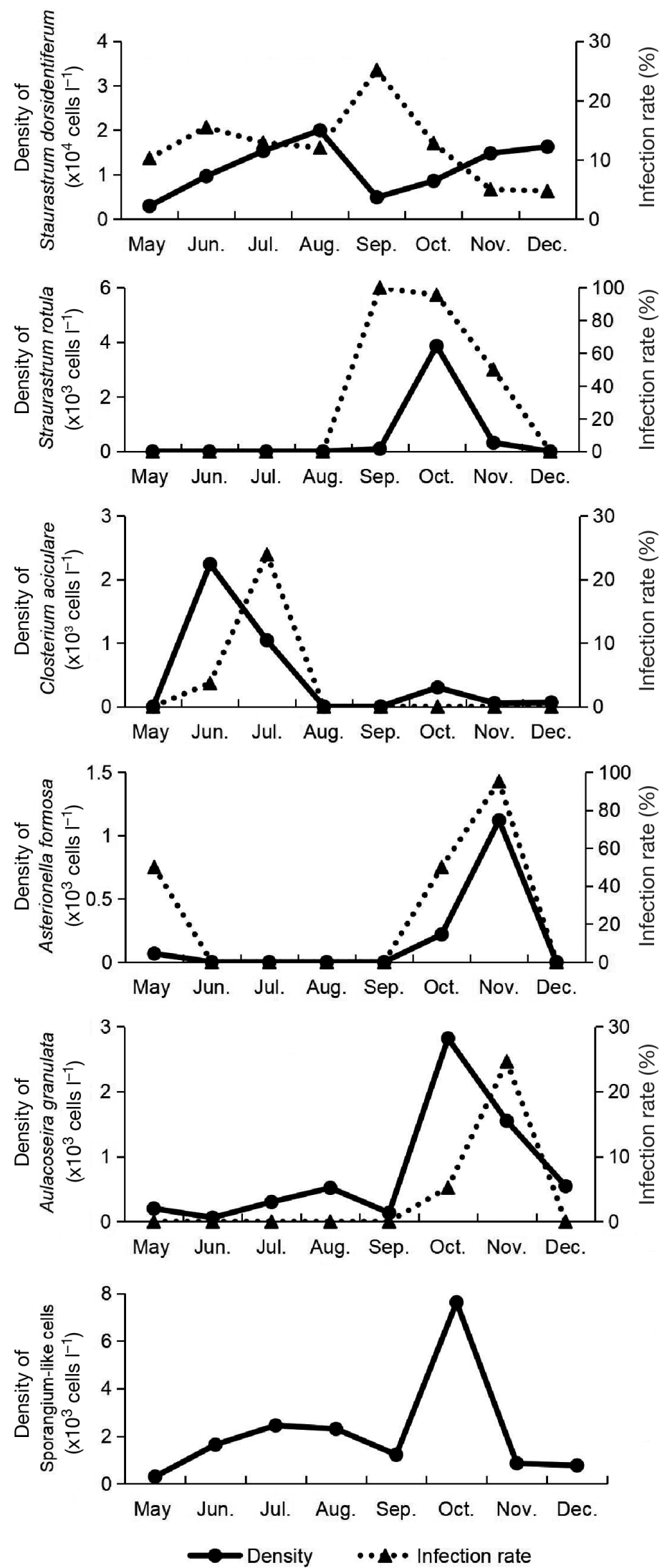

ranged from 4.7 to $25.2 \%$, while chytrid sporangia appeared throughout the sampling periods (Fig. 2). The prevalence of infection in $S$. rotula ranged from 50 to $100 \%$ from September to November. Chytrids on C. aciculare appeared only in June and July, when 3.7 and $23.9 \%$ of the total abundance, respectively, were infected. Chytrids were found on A. formosa in May, October and November, and the prevalence of infection was relatively high, between 50 and $95.2 \%$. A. granulata was mainly infected in October and November, at $5.2-24.6 \%$. The total density of chytrid sporangia was highest in October with $7.6 \times 10^{3}$ cells ml $^{-1}$, and ranged between $0.3 \times 10^{3}$ and $2.4 \times 10^{3}$ cells ml $^{-1}$ in other months (Fig. 2). No infected cells of $M$. hardyi were found, even when it dominated in November and December.

\subsection{Sequence data}

After filtering, 956761 reads included a total of 13757 OTUs in the final matrix. A total of 22264 reads and 311 OTUs were assigned as zoosporic fungal sequences. An additional 204 OTUs were removed from the 311 OTUs as singletons, leaving 107 zoosporic fungal OTUs as the final data set, comprising 22060 reads. OTUs assigned to the phylum Neocallimastigomycota were excluded because phylogenetic analysis indicated that these sequences were not related to Neocallimastigomycota (see Section 4); as a result, 101 OTUs and 15516 reads were used for the analyses (Table 1).

\subsection{Zoosporic fungal diversity and taxonomic characteristics in Lake Biwa}

Three zoosporic fungal phyla, namely Blastocladiomycota $(1.5 \%$ of reads and $2.0 \%$ of OTUs), Chytridiomycota (97.4 and $93.0 \%)$ and Cryptomycota (1.1 and $5.0 \%$ ), were detected. Chytridiomycota was the most diverse and abundant phylum among them. The dominant orders were Chytridiales $38.6 \%$ of reads and $27.7 \%$ of OTUs), Rhizophydiales ( 32.5 and $28.7 \%$ ) and Spizellomycetales (10.4 and $14.9 \%$ ). The

Fig. 2. Temporal changes in cell density of selected phytoplankton species and percentages of the cells with attached chytrid cells (shown as infection rates) from 6 May to 12 December 2016 at Stn 3 in the north basin of Lake Biwa, Japan. Bottom panel shows the total density of chytrid cells attached to host cells during the same time 
Table 1. Sequencing information and 2 indices of alpha diversity (Chao-1 and Shannon's $H$ ) of the zoosporic fungal community (phyla Blastocladiomycota, Chytridiomycota and Cryptomycota) sampled from 6 May to 12 December 2016 at Stn 3 in the north basin of Lake Biwa, Japan, based on BLAST results. OTU: operational taxonomic unit

\begin{tabular}{|lcccc|}
\hline Date & Reads & OTUs & Chao-1 & Shannon's $H$ \\
\hline 6 May & 772 & 25 & 25 & 1.960 \\
22 Jun & 3888 & 23 & 18 & 2.062 \\
5 Jul & 4010 & 16 & 13 & 1.904 \\
4 Aug & 1412 & 18 & 18 & 2.494 \\
12 Sep & 1978 & 28 & 25 & 2.152 \\
18 Oct & 1841 & 28 & 28 & 2.598 \\
22 Nov & 342 & 18 & 18 & 2.296 \\
12 Dec & 1273 & 21 & 22 & 2.378 \\
Final matrix & 15516 & 101 & & \\
& & & & \\
\hline
\end{tabular}

dominant genera were Chytriomyces (23.8 and $10.9 \%)$, Rhizophydium (13.0 and $14.9 \%$ ) and Phlyctochytrium (10.6 and $4.0 \%$ ).

A rarefied OTU table was generated at 342 sequences per sample. Chao-1 and Shannon's $H$ indices in fungal communities varied from 13 to 28 and from 1.904 to 2.598 , respectively (Table 1 ). Both Chao-1 and Shannon's $H$ showed the highest diversity in October, when chytrid cells showed the largest density (Fig. 2). Gephi network analysis is shown in Fig. 3. Results showed that the number of OTUs was very different in all months, and unique OTUs appeared in each month. The highest value of 11 unique OTUs was found in October, while the lowest value of 3 unique OTUs was found in November.

\subsection{Temporal variations in zoosporic fungal communities}

Temporal variations in zoosporic fungal communities were found during the study period. At the level of order, although the composition of the OTUs did not differ significantly throughout the study period, their sequence compositions showed temporal changes (Fig. 4). The sequence composition of Chytridiales, Rhizophydiales, Spizellomycetales and Monoblepharidales varied from 7.3 to $72.8 \%$, from 13.0 to $56.2 \%$, from 3.3 to $26.7 \%$ and from 0 to $19.8 \%$, respectively, during the study period. Chytridiales dominated in May, June and September $(>65 \%)$ but not in other months $(<35 \%)$. Spizellomycetales were high contributors $(>21 \%)$ from October to December but not in other months $(<9 \%)$. Cladochytriales accounted for $>27 \%$ in November but were not detected from June to September. Only 3 known genera (Chytriomyces, Boothiomyces and Rhizophydium) were detected throughout the study period. Six genera (Allomyces, Dendrochytridium, Rhizoclosmatium, Gromochytrium, Gonapodya and Monoblepharis) were detected on only 1 occasion.

Phylogenetic analysis revealed that most of the OTUs did not have any close affinity with cultured chytrids, but that some were assigned to known species: Staurastromyces oculus, Pateramyces corrientinensis, Globomyces pollinis-pini, Urceomyces sphaerocarpus, Pendulichytrium sphaericum, Rhizoclosmatium sp. and Pseudorhizidium endosporangiatum (Fig. 5). Two OTUs were clustered into Zygophlyctidales (Seto et al. 2020).

Three OTUs were matched with 3 chytrid species parasitic on phytoplankton: $S$. oculus as an obligate parasite of the green alga Staurastrum sp. (Van den Wyngaert et al. 2017), P. sphaericum as an obligate parasite of the diatom A. granulata (Seto \& Degawa 2018) and Zygophlyctis asterionellae as an obligate parasite of the diatom A. formosa (Seto et al. 2020). The sequences of these 3 chytrids were always detected when sporangia of chytrids on each host phytoplankton species were found during microscopic examination (Fig. 6). However, their sequences were sometimes not detected even when chytrid sporangia

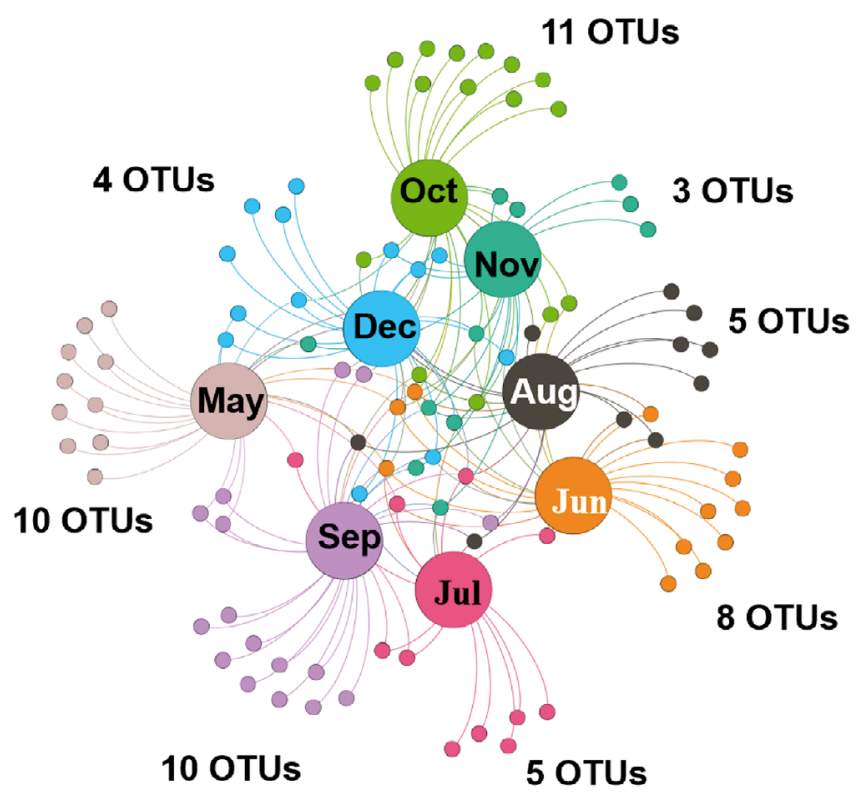

Fig. 3. Gephi network diagram illustrating Blastocladiomycota, Chytridiomycota and Cryptomycota from 6 May to 12 December 2016 at Stn 3 in the north basin of Lake Biwa, Japan, highlighting the number of unique operational taxonomic units (OTUs) based on BLAST results. A small circle (representative OTU) that is only connected to 1 large circle (representative sample) indicates a unique OTU. The number of unique OTUs is shown for each month 
A



B



Fig. 4. Composition of zoosporic fungal orders (Blastocladiomycota, Chytridiomycota and Cryptomycota) in (A) operational taxonomic units (OTUs) and (B) number of sequences. Samples were collected from 6 May to 12 December 2016 at Stn 3 in the north basin of Lake Biwa, Japan; fungal composition is based on BLAST results. Asterisk indicates phylum level

were found; thus, dynamics based on sequences and dynamics based on sporangia counts differed from each other.

\section{DISCUSSION}

We detected diverse zoosporic fungi with the LSU region as a marker gene: a total of 101 OTUs in 3 zoosporic fungal phyla (Blastocladiomycota, Chytridiomycota and Cryptomycota) and 8 known species (Table 2). In our previous study based on the ITS region, many of the sequences were not assigned or were identified as 'unclassified fungi' (Song et al. 2018). Only 1 zoosporic fungal phylum (Chytridiomycota) with 35 OTUs was detected, and 1 parasitic chytrid (Staurastromyces oculus) was identified. Compared with the LSU region, there is less information on Chytridiomycota in the reference database of the ITS region for aquatic fungi (Wurzbacher et al. 2016).

Due to lack of chytrid data in public sequence databases, few OTUs were identified as known chytrids in the present study. The remaining OTUs were mostly assigned as unknown taxa, and therefore it is difficult to determine their ecology (Frenken et al. 2017). Eight OTUs, however, were identified as previously known species, and we were able to determine their ecological characteristics (i.e. their nutritional modes, whether they were parasites or saprotrophs, their hosts/substrates and habitats) (Table 3).
Three OTUs were matched with 3 parasitic chytrid species of phytoplankton: $S$. oculus (Rhizophydiales, Staurastromycetaceae) infecting Staurastrum sp. (Van den Wyngaert et al. 2017), Pendulichytrium sphaericum (Chytridiales, Chytriomycetaceae) infecting $\mathrm{Au}$ lacoseira granulata (Seto \& Degawa 2018) and Zygophlyctis asterionellae infecting Asterionella formosa (Seto et al. 2020). The morphology of sporangia attached to Staurastrum dorsidentiferum was consistent with that of Staurastromyces oculus: it had an encysted zoospore in the isthmus region of the host, while sporangia attached on Staurastrum rotula were different from any stages of $S$. oculus (Van den Wyngaert et al. 2017). Different patterns in the abundance of sporangia on $S$. rotula and the relative abundance of the sequence reads of S. oculus (Fig. 6) also indicated that the chytrids infecting $S$. rotula must have been different species. The chytrid infecting $S$. dorsidentiferum may have been $S$. oculus, although there may have been other species infecting $S$. dorsidentiferum when sequence reads of $S$. oculus were not detected.

According to microscopic analysis, the morphology of sporangia attached to A. granulata was consistent with the morphology of $P$. sphaericum: the mature zoosporangium was spherical and stalked (Seto \& Degawa 2018) (Fig. S3), and the patterns of read percentage and abundance of sporangia also matched (Fig. 6); thus, it is likely that the chytrid infecting $A$. granulata was $P$. sphaericum. The morphology of sporangia attached to $A$. formosa was consistent with 




0.05

Fig. 5. Phylogenetic tree of the large number of operational taxonomic units (OTUs, designated as 'denovo' in the tree) in chytrids, with large subunit (LSU) sequences of known fungi, based on the maximum likelihood analysis. Samples were collected from 6 May to 12 December 2016 at Stn 3 in the north basin of Lake Biwa, Japan 



Fig. 6. Comparison of known chytrids between metabarcoding analysis and microscopic counting results from 6 May to 12 December 2016 at Stn 3 in the north basin of Lake Biwa, Japan

that of $Z$. asterionellae, as the encysted zoospore was spherical and the developing thallus was obpyriform (Seto et al. 2017) (Fig. S3). Sequences of Z. asterionellae were always detected when chytrid sporangia on $A$. formosa were observed. The peak of $Z$. asterionellae read percentage was a month earlier than the abundance of sporangia (Fig. 6). Since our DNA analysis targeted zoospores $(2-20 \mu \mathrm{m})$, instead of sporangia, it is likely that the detected timing recorded a slight gap between zoospores and sporangia. Rhizophydium planktonicum is also a parasite of $A$. formosa and possesses similar morphology to Z. asterionellae (Seto et al. 2017), but it was not detected with metabarcording analysis in this study.

Some other parasitic chytrids might be included in the unknown OTUs. We found high infection rates in Closterium aciculare in July (Fig. 2) but could not identify any OTUs corresponding to parasitic chytrids on C. aciculare. Although chytrids on C. aciculare have been reported previously (Holfeld 1998, Fernández et al. 2011), no DNA sequence data are available for these chytrids. Among all the detected Chytridiomycota sequences in our metabarcoding analysis, 1 unknown chytrid OTU ('denovo 49959') might have been a parasite of $C$. aciculare, which showed relatively high abundance in July when the number of chytrid sporangia on $C$. aciculare was at its highest (Fig. 4). Phylogenetic analysis indicated that denovo 49959 may be a novel clade in the Rhizophydiales (Fig. 5). Further studies are necessary to clarify this, and to identify the parasitic chytrid of $C$. aciculare in Lake Biwa.

In the present study, the chytrid infection rates on 5 large dominant phytoplankton varied along with the abundances of their hosts. The temporal variation in hosts can be strongly influenced by the parasitic fungi, and especially by that of host-specific fungi (Holfeld 2000, Ibelings et al. 2004). In fact, chytrid infection has been shown to affect phytoplankton dynamics on S. dorsidentiferum in Lake Biwa (Kagami et al. 2004). Chytrid infection-mediated effects on host phytoplankton dynamics may be plausible in this lake. Compared with the previous study (Kagami et al. 2004), however, the prevalence of infection was low in our study. Since we only took monthly samples, we need more frequent sampling to identify the hostparasite relationships in the lake.

The OTUs identified as Pateramyces corrientinensis, Globomyces pollinis-pini, Urceomyces sphaerocarpus, Rhizoclosmatium sp. and Pseudorhizidium endosporangiatum in the present study may be saprotrophic species, according to the literature (Table 3). They contributed a very small proportion of total chytrid reads $(<10 \%)$, except in December $(21 \%)$. P. corrientinensis, G. pollinis-pini and $U$. sphaerocarpus have been detected from pollen as substrates in aquatic habitats (Letcher et al. 2008). $P$. endosporangiatum has been isolated from pollen in 
Table 2. Comparison of the detected zoosporic fungal phyla and orders using internal transcribed spacer (ITS) from our previous study (Song et al. 2018) and large subunit (LSU) regions by metabarcoding analysis. Samples were collected at Stn 3 in Lake Biwa, Japan. Plus (+) represents occurrence. Blank cells therefore indicate that these orders were not found. OTU: operational taxonomic unit

\begin{tabular}{|c|c|c|c|c|c|c|c|c|c|c|c|c|c|}
\hline \multirow{2}{*}{ Phylum } & \multirow[t]{2}{*}{ Order } & \multicolumn{4}{|c|}{ ITS (sampling year: 2015) } & \multicolumn{8}{|c|}{ — LSU (sampling year: 2016) } \\
\hline & & Apr & May & Jul & Sep & May & Jun & Jul & Aug & Sep & Oct & Nov & Dec \\
\hline Blastocladiomycota & Blastocladiales & & & & & & + & & + & & + & & \\
\hline \multirow[t]{8}{*}{ Chytridiomycota } & Chytridiales & & + & + & + & + & + & + & + & + & + & + & + \\
\hline & Cladochytridiales & & & & & + & & & & & + & + & + \\
\hline & Gromochytriales & & & & & + & & & & & & & \\
\hline & Rhizophlyctidales & & & + & & + & & & + & & + & & \\
\hline & Rhizophydiales & + & + & + & & + & + & + & + & + & + & + & + \\
\hline & Spizellomycetales & & & + & & + & + & + & + & + & + & + & + \\
\hline & Monoblepharidales & & & & & & & & + & + & + & + & \\
\hline & Harpochytriales & & & & & + & + & + & + & + & + & & \\
\hline \multirow[t]{2}{*}{ Cryptomycota } & & & & & & & & & & + & + & + & \\
\hline & Number of OTUs & 7 & 15 & 18 & 5 & 25 & 23 & 16 & 18 & 28 & 28 & 18 & 21 \\
\hline
\end{tabular}

Table 3. List of identified chytrid species detected from 6 May to 12 December 2016 at Stn 3 in the north basin of Lake Biwa, Japan, including their ecology and hosts. -/-: not reported

\begin{tabular}{|lccc|}
\hline Species & Ecology & Habitat/host & Reference \\
\hline Zygophlyctis asterionellae & Obligate parasite & Aquatic/Asterionella formosa & Seto et al. (2020) \\
Staurastromyces oculus & Obligate parasite & Aquatic/Staurastrum sp. & Van den Wyngaert et al. (2017) \\
Pendulichytrium sphaericum & Obligate parasite & Aquatic/Aulacoseira granulata & Seto \& Degawa (2018) \\
Urceomyces sphaerocarpus & Saprotroph & Aquatic/pollen & Letcher et al. (2008) \\
Globomyces pollinis-pini & Saprotroph & Aquatic/pollen & Letcher et al. (2008) \\
Pateramyces corrientinensis & Saprotroph & Aquatic/pollen & Letcher et al. (2008) \\
Pseudorhizidium endosporangiatum & Saprotroph & Soil/pollen & Powell et al. (2013) \\
Rhizoclosmatium sp. JEL347-h & Saprotroph & $-/-$ & James et al. (2006) \\
\hline
\end{tabular}

garden soil (Powell et al. 2013), and therefore in this study, it may have been transferred from terrestrial to aquatic habitats by wind action (Wurzbacher et al. 2010). Saprotrophic zoosporic fungi may depend strongly on substrate quality in the pelagic zone (i.e. carbon sources, sestonic C:N and N:P supply ratios from the watersheds) (Findlay et al. 2002, Güsewell \& Gessner 2009), although we were unable to identify the factors influencing the dynamics of saprotrophic fungi in this study.

Some OTUs showed the closest match with Neocallimastigomycota in this study (Table S3). This phylum is regarded as consisting of obligately anaerobic rumen fungi, which are found widely in the guts of ruminants (Gruninger et al. 2014). Both of our sequences matched 2 environmental sequences in GenBank, i.e. LLMB10_1 and LLME10_2 (accession numbers JN049554 and JN049555, respectively), from Lakes Tuscaloosa and Lurleen (Alabama, USA), respectively (Lefèvre et al. 2012), which were affiliated to Neocallimastigomycota. However, a BLAST search and preliminary phylogenetic analysis indicated that these sequences are not related to Neocallimastigomycota. LLMB10_1 was ca. 96\% identical to the green algae Chlamydomonas spp. in the BLAST search. In our phylogenetic analysis (Fig. S4), LLME10_2 was not related to Neocallimastigomycota and showed a long branch in Chytridiomycota, indicating that the phylogenetic position of this sequence is uncertain. Wurzbacher et al. (2016) also found an OTU assigned to the Neocallimastigomycota sequence in Lake Stechlin (Germany), but concluded through phylogenetic analysis that the OTU was not related to Neocallimastigomycota but was distributed among other fungal lineages.

In our study, the sequences of the known chytrids were always detected by meta-barcoding analysis when they were observed by microscopic analysis. However, sometimes no sequences were detected even if the chytrid sporangia on phytoplankton were observed. One reason for this may be the nano-sized particle fraction $(2-20 \mu \mathrm{m})$ that we targeted in metabarcoding analysis, but not in sporangia attached to large phytoplankton species (>20 $\mu \mathrm{m})$. Metabarcod- 
ing analysis was therefore unable to detect chytrid sequences when they mainly presented as sporangia on large phytoplankton. Although calcofluor white stains not only chytrids but also other fungi and protists with cellulose, we observed the morphology of sporangia carefully, and concluded that the detected sporangia were chytrids. The size threshold for chytrid infection has been uncertain, although chytrids tend to infect large hosts (Kagami et al. 2007a). In this study, we never found any chytrids that infected small phytoplankton, although it could be possible that many unexplained OTUs could imply miscounting those attached to small phytoplankton $(\leq 20 \mu \mathrm{m})$. Another reason for this may be the primer bias, since we detected only a few fungi, and most of the sequences belonged to other eukaryotes. Further studies combining microscopic observations and metabarcoding analysis may reveal the existence of more diverse fungi in the water column of Lake Biwa.

Acknowledgements. This work was supported by a Grant-inAid for Scientific Research (B) (grant number 25281012) from the Ministry of Education to M.K. and a Chinese Scholarship Council to P.S. We thank Captain Bun-ichiro Kaigai for help in collecting samples from RV 'Hassaka,' and members of our laboratories for supporting all laboratory work. We thank Dr. Xin Liu for helping in the preparation of the figures. We thank Edanz Group (https://en-author-services.edanzgroup. com/ac) for editing an early draft of this manuscript.

\section{LITERATURE CITED}

Capella-Gutiérrez S, Silla-Martínez JM, Gabaldón T (2009) trimAl: a tool for automated alignment trimming in large-scale phylogenetic analyses. Bioinformatics 25: 1972-1973

Caporaso JG, Kuczynski J, Stombaugh J, Bittinger K, Bushman FD, Costello EK (2010) QIIME allows analysis of highthroughput community sequencing data. Nat Methods 7 : 335-336

Chao A (1984) Nonparametric estimation of the number of classes in a population. Scand J Stat 11:265-270

Edgar RC (2010) Search and clustering orders of magnitude faster than BLAST. Bioinformatics 26:2460-2461

Edgar RC (2013) UPARSE: highly accurate OTU sequences from microbial amplicon reads. Nat Methods 10:996-998

Fernández C, Parodi ER, Cáceres EJ (2011) Impact of the fungal parasite Rhizophydium couchii (Chytridiomycota) on the population dynamics of the freshwater alga Closterium aciculare (Chlorophyta). Nova Hedwigia 93: 97-106

Findlay S, Tank J, Dye S, Valett HM and others (2002) A cross-system comparison of bacterial and fungal biomass in detritus pools of headwater streams. Microb Ecol 43: $55-66$

Frenken T, Alacid E, Berger SA, Bourne EC and others (2017) Integrating chytrid fungal parasites into plankton ecology: research gaps and needs. Environ Microbiol 19: 3802-3822
Garvetto A, Badis Y, Perrineau MM, Rad-Menéndez C, Bresnan E, Gachon MM (2019) Chytrid infecting the bloom-forming marine diatom Skeletonema sp.: morphology, phylogeny and distribution of a novel species within the Rhizophydiales. Fungal Biol 123:471-480

Grossart HP, Van den Wyngaert S, Kagami M, Wurzbacher C, Cunliffe M, Rojas-Jimenez K (2019) Fungi in aquatic ecosystems. Nat Rev Microbiol 17:339-354

* Gruninger RJ, Puniya AK, Callaghan TM, Edwards JE and others (2014) Anaerobic fungi (phylum Neocallimastigomycota): advances in understanding their taxonomy, life cycle, ecology, role and biotechnological potential. FEMS Microbiol Ecol 90:1-17

Güsewell S, Gessner MO (2009) N:P ratios influence litter decomposition and colonization by fungi and bacteria in microcosms. Funct Ecol 23:211-219

* Heeger F, Wurzbacher C, Bourne EC, Mazzoni CJ, Monaghan MT, Yu D (2019) Combining the 5.8S and ITS2 to improve classification of fungi. Methods Ecol Evol 10: 1702-1711

*Hibbett DS, Binder M, Bischoff JF, Blackwell M and others (2007) A higher-level phylogenetic classification of the Fungi. Mycol Res 111:509-547

Holfeld H (1998) Fungal infections of the phytoplankton: seasonality, minimal host density, and specificity in a mesotrophic lake. New Phytol 138:507-517

Holfeld H (2000) Infection of the single-celled diatom Stephanodiscus alpinus by the chytrid Zygorhizidium: parasite distribution within host population, changes in host cell size, and host-parasite size relationship. Limnol Oceanogr 45:1440-1444

*Hopple JS Jr, Vilgalys R (1994) Phylogenetic relationships among coprinoid taxa and allies based on data from restriction site mapping of nuclear rDNA. Mycologia 86: 96-107

Ibelings BW, De Bruin A, Kagami M, Rijkeboer M, Brehm M, Donk EV (2004) Host parasite interactions between freshwater phytoplankton and chytrid fungi (Chytridiomycota) 1. J Phycol 40:437-453

* Ishida S, Nozaki D, Grossart HP, Kagami M (2015) Novel basal, fungal lineages from freshwater phytoplankton and lake samples. Environ Microbiol Rep 7:435-441

James TY, Letcher PM, Longcore JE, Mozley-Standridge SE and others (2006) A molecular phylogeny of the flagellated fungi (Chytridiomycota) and description of a new phylum (Blastocladiomycota). Mycologia 98:860-871

Jobard M, Rasconi S, Sime-Ngando T (2010) Fluorescence in situ hybridization of uncultured zoosporic fungi: testing with clone-FISH and application to freshwater samples using CARD-FISH. J Microbiol Methods 83: 236-243

Kagami M, Urabe J (2002) Mortality of the planktonic desmid, Staurastrum dorsidentiferum, due to interplay of fungal parasitism and low light conditions. Verh Int Verein Theor Angew Limnol 28:1001-1005

Kagami M, Van Donk E, de Bruin A, Rijkeboer M, Ibelings BW (2004) Daphnia can protect diatoms from fungal parasitism. Limnol Oceanogr 49:680-685

Kagami M, Gurung TB, Yoshida T, Urabe J (2006) To sink or to be lysed? Contrasting fate of two large phytoplankton species in Lake Biwa. Limnol Oceanogr 51:2775-2786

Kagami M, de Bruin A, Ibelings BW, Van Donk E (2007a) Parasitic chytrids: their effects on phytoplankton communities and food-web dynamics. Hydrobiologia 578: $113-129$ 
Kagami M, von Elert E, Ibelings BW, Bruin A, Van Donk E (2007b) The parasitic chytrid, Zygorhizidium, facilitates the growth of the cladoceran zooplankter, Daphnia, in cultures of the inedible alga, Asterionella. Proc R Soc B 274:1561-1566

Karpov SA, Mamkaeva MA, Aleoshin VV, Nassonova E, Lilje O, Gleason FH (2014) Morphology, phylogeny, and ecology of the aphelids (Aphelidea, Opisthokonta) and proposal for the new superphylum Opisthosporidia. Front Microbiol 5:112

Katoh K, Standley DM (2013) MAFFT multiple sequence alignment software version 7: improvements in performance and usability. Mol Biol Evol 30:772-780

Kilias ES, Junges L, Šupraha L, Leonard G, Metfies K, Richards TA (2020) Chytrid fungi distribution and cooccurrence with diatoms correlate with sea ice melt in the Arctic Ocean. Commun Biol 3:183

Lefèvre E, Bardot C, Noël C, Carrias JF (2007) Unveiling fungal zooflagellates as members of freshwater picoeukaryotes: evidence from a molecular diversity study in a deep meromictic lake. Environ Microbiol 9:61-71

K Lefèvre E, Letcher PM, Powell MJ (2012) Temporal variation of the small eukaryotic community in two freshwater lakes: emphasis on zoosporic fungi. Aquat Microb Ecol 67:91-105

Letcher PM, Powell MJ (2018) A taxonomic summary and revision of Rozella (Cryptomycota). IMA Fungus 9:383-399

Letcher PM, Vélez CG, Barrantes ME, Powell MJ and others (2008) Ultrastructural and molecular analyses of Rhizophydiales (Chytridiomycota) isolates from North America and Argentina. Mycol Res 112:759-782

Magoč T, Salzberg SL (2011) FLASH: fast length adjustment of short reads to improve genome assemblies. Bioinformatics 27:2957-2963

Powell MJ, Letcher PM, Longcore JE (2013) Pseudorhizidium is a new genus with distinct zoospore ultrastructure in the order Chytridiales. Mycologia 105:496-507

Rehner SA, Samuels GJ (1995) Molecular systematics of the

Editorial responsibility: Paul del Giorgio,

Montreal, Quebec, Canada

Reviewed by: 2 anonymous referees
Hypocreales: a teleomorph gene phylogeny and the status of their anamorphs. Can J Bot 73:816-823

* Seto K, Degawa Y (2018) Pendulichytrium sphaericum gen. et sp. nov. (Chytridiales, Chytriomycetaceae), a new chytrid parasitic on the diatom, Aulacoseira granulata. Mycoscience 59:59-66

* Seto K, Kagami M, Degawa Y (2017) Phylogenetic position of parasitic chytrids on diatoms: characterization of a novel clade in Chytridiomycota. J Eukaryot Microbiol 64: 383-393

Seto K, Van den Wyngaert S, Degawa Y, Kagami M (2020) Taxonomic revision of the genus Zygorhizidium: Zygorhizidiales and Zygophlyctidales ord. nov. (Chytridiomycetes, Chytridiomycota). Fungal Syst Evol 5:17-38

* Shannon CE (2001) A mathematical theory of communication. SIGMOBILE Mob Comput Commun Rev 5:3-55

* Song P, Tanabe S, Yi R, Kagami M, Liu X, Ban S (2018) Fungal community structure at pelagic and littoral sites in Lake Biwa determined with high-throughput sequencing. Limnology 19:241-251

Stamatakis A (2014) RAxML version 8: a tool for phylogenetic analysis and post-analysis of large phylogenies. Bioinformatics 30:1312-1313

*Van den Wyngaert S, Seto K, Rojas-Jimenez K, Kagami M, Grossart HP (2017) A new parasitic chytrid, Staurastromyces oculus (Rhizophydiales, Staurastromycetaceae fam. nov.), infecting the freshwater desmid Staurastrum sp. Protist 168:392-407

*Wurzbacher C, Bärlocher F, Grossart HP (2010) Fungi in lake ecosystems. Aquat Microb Ecol 59:125-149

* Wurzbacher C, Warthmann N, Bourne E, Attermeyer K and others (2016) High habitat-specificity in fungal communities in oligo-mesotrophic, temperate Lake Stechlin (north-east Germany). MycoKeys 16:17-44

* Yoneya K, Miki T, Van den Wyngaert S, Grossart HP, Kagami M (2021) Non-random patterns of chytrid infections on phytoplankton host cells: mathematical and chemical ecology approaches. Aquat Microb Ecol 87:1-15

Submitted: November 18, 2020

Accepted: April 26, 2021

Proofs received from author(s): June 13, 2021 